\title{
Approach to Corporate Education of Employees in Companies in the Czech Republic, Russia, Slovakia and Ukraine: A Comparative Analysis
}

\author{
Zdeněk Caha $^{1 *}$, Iva Klementová ${ }^{1}$, Michaela Procházková1 $^{1}$, Mario Bogdanovic ${ }^{2}$, Michaela Ruso $^{1}$ \\ ${ }^{1}$ Institute of Technology and Business, Faculty of Corporate Strategy, Okružní 517/10, 37001 Ceske Budejovice, Czech Republic \\ ${ }^{2}$ Istrian University of Applied Sciences in Pula, Croatia
}

\begin{abstract}
Effective and systematic corporate education is a key factor for competitiveness the current turbulent economy. The results presented in this paper are based on a questionnaire survey. The research was carried out on a sample set of Czech, Russian, Slovak and Ukrainian companies. The aim of the survey was to determine to what extent companies in four post-communist countries apply a strategic approach to education, which, among other things, is linked to the presence of long-term and annual education plans. The results of the research showed that micro-companies and small companies in particular do not do so. The research also revealed that some companies, even though they declare they have an LTEP/AEP in place, are not adhering to their plans.
\end{abstract}

Key words: Czech Republic; Russia; Slovakia; Ukraine; strategic approach; corporate education; plan

\section{Introduction}

Effective and systematic corporate education, as a part of overall company strategy, has been shown to be a key factor in maintaining a competitive advantage in the current knowledge economy [1,2]. According to Armstrong [3], strategic education and development, like strategic HR management, plays a key role in the achievement of an organisation's success. Within this context, employees are, without a doubt, one of the most important resources a company possesses when it comes to generating potential competitive advantage [4]. It is therefore important to educate and develop employees systematically and effectively [5,6]. The education of an organisation's employees is the most effective if it has a cyclical character, is based on the education strategy and policy of the particular organisation, and is in compliance with the overall strategy of the organisation [7]. One reason for the increasing interest in entrepreneurship education is the positive impact of entrepreneurship on sustainable economic growth. The basic cycle for the systematic education of employees of an organisation consists of: the identification of the need for education; the planning of the education; the implementation of the education process; and the assessment of the results and effectiveness of the education programme. The systematic education of employees and the conceptual planning and management of their careers supports the achievement of an organisation's strategic goals and contributes to the long-term competitiveness of a company [8]. Bencsik and Sólyom [9] also claim that the more a company is able to maintain, develop and utilise the knowledge of its employees, the more it is able to achieve business success, as knowledge becomes a resource of long-term competitiveness and an advantage from the business strategy point of view. Rauch and Hatak [10] underlines the importance of the strategic planning of corporate education by claiming that the cost of education should represent a profitable investment, which is why education planning should be based on an analysis of the present situation, as well as the future needs and demands of individual work positions. According to Moifrrnkuzzx et al. [11], the presence of development and education specialists is an indication of a strategic approach, particularly in large and medium-sized companies.

According to the results of an international survey conducted in 2010 [12], less than a third of companies reported having written education plans or similar education programmes in place, and less than half reported having an allocated budget for such activities. Estimations made by the International Labour Organisation [13] show that a $1 \%$ increase in the number of days spent on education leads to a productivity increase of $3 \%$ in a company. Good quality training enables people to develop their capacities and to exploit social opportunities, as well as improves the productivity of employees and companies. These factors combined contribute to the future strengthening of innovation and development and encourages domestic as well as international investment. This in turn, creates jobs, reduces unemployment, leads to higher levels of pay and reduces social inequality. Collier, et al. [14] claim on the basis of their own research, that companies that systematically educate their employees have a $13 \%$ higher probability that they will survive. They go on to say that more research is required into the long-term impact of education or human capital on a company's overall performance. Kitching and Blackburn [15] confirm the positive impact of a strategic approach to education. Korenková [16] is convinced that it is the people who work for a company that help it distinguish itself from others and who determine

\footnotetext{
${ }^{*}$ Corresponding author: caha@mail.vstecb.cz
} 
whether a company will be successful or not through their active and creative approach to innovation and to customers themselves. Support for education is therefore crucial for maintaining competitiveness. Staff education and development should therefore be a part of overall company strategy and policy, and should be a coherent and systematic process. Korenková goes on to state that large companies prefer an active and systematic approach to education, whereas a random approach prevails in medium-sized companies and a passive approach in small companies. These different approaches are largely determined by the availability of funds, whereby the majority of small companies prefer to invest into innovation and improvements in technologies and leave education to the employees themselves. Tej and Sláviková and Hrvolová [17] divided companies into three categories according to their approach to education, namely companies without an education strategy, companies with a non-systematic strategy and companies with a positive systematic strategy. They hold the view that companies achieve competitive advantages through their employees and that, although the effectiveness of the money invested into education is often difficult to enumerate, education is an investment that certainly pays off for companies. Cagán̆ová, et al. [18] characterise the orientation of companies active in the field of education and employee development in Slovakia and present the results of research conducted in 340 companies in 2012. Their working assumption was that education and a comprehensive approach to education are the characteristics of an innovative organisation. They concluded that organisations should become so-called "learning companies" with the aim of achieving permanent education focused on the improvement of performance not only on a short-term basis, but also on a long-term one.

\section{Methodology}

The aim of the research was to determine to what extent companies in four post-communist countries apply a strategic approach to education, which, among other things, is linked to the presence of long-term (LTEP) and annual education plans (AEP). In relation to the research goal, the following three research questions were formulated:

RQ1: To what extent do companies in the four post-communist countries (the Czech Republic - CR, Russia - RUS, Slovakia -SLO, and Ukraine - UKR) apply a strategic approach to corporate learning (existence of long-term training plans, annual training plans).

RQ2: If there are LTTP or ATP, to what extent they are followed?

RQ3: To what extent does the existence of LTTP or ATP depend on the company size and the scope of its operations in the individual countries?

The research was conducted from mid-2016 to January 2018. The data was obtained by means of a questionnaire survey distributed among selected companies in the Czech Republic, Russia, Slovakia and Ukraine. In addition to establishing basic identification data on the companies (size, number of employees, scope of activities), the questionnaire also sought to determine data on the long-term education plans (LTEP) and annual education plans (AEP) of the respondents. The questionnaire was addressed to personnel managers or other competent managers or owners of companies. The respondents could choose between a printed or an electronic version of the questionnaire by means of an electronic link within the Google Disc web platform. The data obtained this way was entered into Excel, checked and subsequently adjusted for use in the R programme. The basic methods of inductive and descriptive statistics particularly contingency tables and graphs, Chi-square tests of independence, two-selection asymptotic U-tests and regression methods with artificial variables - logit regression model were applied to the data analysis [19].

The results are presented by means of tables and graphs. The statistical analysis of the existence of an LTEP and the existence of an AEP in companies in the Czech Republic (CR), Russia (RUS), Slovakia (SLO) and Ukraine (UKR) were processed in relation to company size, number of employees, and scope of company activity.

The following part of this paper includes a written and statistical analysis and evaluation of the existence of an LTEP (AEP) in the selected companies in the individual countries. In cases where the information on corporate education was missing, it was assumed that such an education plan did not exist. The differences in terms of the existence of an LTEP in Czech, Russian and Slovak companies was not great. The proportion among Ukrainian companies was less than half. As previously stated, the significance of these differences was also assessed by means of statistical tests. In addition, the adherence to an LTEP was assessed by means of contingency tables and graphs. Relative frequencies were calculated for the different numbers of companies in the individual countries.

The dependence of the existence of an LTEP (AEP) on company size and scope of company activity in the individual countries was also analysed by means of contingency tables and graphs. The hypothesis that the proportion of companies with an LTEP (AEP) grows in relation to company size was also tested. The dependence of the median proportion of companies with an LTEP (AEP) on the number of employees and on country was quantitatively examined and compared by means of logistic regression.

\section{Results and discussion}

The first step of the analysis was to look at the existence of an LTEP in companies according to country. The results are presented in the contingency tables $(1,2)$ 
Table 1. Numbers of companies with and without an LTEP

\begin{tabular}{|l|cc|c|}
\hline & Yes & No & Total \\
\hline Czech Republic & 290 & 319 & 609 \\
Russia & 22 & 28 & 50 \\
Slovakia & 45 & 40 & 85 \\
Ukraine & 29 & 116 & 145 \\
\hline Total & 386 & 503 & 889 \\
\hline
\end{tabular}

Source: Authors

Table 2. Proportion of companies with and without an LTEP (in \%)

\begin{tabular}{|l|cc|c|}
\hline & Yes & No & Total \\
\hline Czech Republic & $47.6 \%$ & $52.4 \%$ & $100.0 \%$ \\
Russia & $44.0 \%$ & $56.0 \%$ & $100.0 \%$ \\
Slovakia & $52.9 \%$ & $47.1 \%$ & $100.0 \%$ \\
Ukraine & $20.0 \%$ & $80.0 \%$ & $100.0 \%$ \\
\hline Total & $43.4 \%$ & $56.6 \%$ & $100.0 \%$ \\
\hline \multicolumn{4}{|l}{ Source: Authors }
\end{tabular}

It is clear that the country with the highest number of companies with an LTEP is Slovakia (52.9\%), followed by the Czech Republic (47.6\%) and Russia (44.0\%). The country with the lowest number $(20.0 \%)$ is Ukraine. The significance of the dependence of the proportion of companies with an LTEP on the country of origin was proven by a Chi-square test of independence. The results (see Table 2) were as follows: $X$-squared $=39.89 ; \mathrm{df}=3 ; \mathrm{p}$-value $=1.113 .10^{-08}$. This means that the statistical significance of this dependence was confirmed at the significance level of 5\%. However, it should be noted that the results may be influenced by the low number of Russian companies in the sample set.

Two-selection asymptotic U-tests were conducted on the population proportions to determine the significance of the difference in the proportions of companies with an LTEP in the individual countries. To do this, the population proportions of companies with an LTEP in the individual countries were identified by the symbols $\pi \mathrm{CR}, \pi \mathrm{RUS}, \pi \mathrm{SLO}, \pi \mathrm{UKR}$, the corresponding selection proportions identified by the symbols pCR, pRUS, pSLO, pUKR, and the corresponding total numbers of companies identified by the symbols nCR, nRUS, nSLO, nUKR.

Firstly, the companies with an LTEP in the Czech Republic and in Russia were compared. The data presented in Table 1 shows that the existence of an LTEP is lower in Russia, with only 22 out of the 50 Russian companies (44\%) having one. Of the 609 Czech companies that participated in the research, 290 have an LTEP in place (47.62\%) - see Table 1 . A zero hypothesis H0: $\pi \mathrm{CR}=\pi \mathrm{RUS}$ was subsequently tested against an alternative hypothesis $\mathrm{H} 1: \pi \mathrm{CR}>\pi \mathrm{RUS}$. The test statistic was

$$
U=\frac{p_{\check{C} R}-p_{R U S}}{\sqrt{p^{*}\left(1-p^{*}\right)\left(\frac{1}{n_{\check{C} R}}+\frac{1}{n_{R U S}}\right)}}, \text { where } p^{*}=\frac{p_{\check{C} R} n_{\check{C} R}+p_{R U S} n_{R U S}}{n_{\check{C} R}+n_{R U S}}
$$

On the basis of the data in Tables 1 and 2

$$
p^{*}=\frac{p_{\check{C} R} n_{\check{C} R}+p_{R U S} n_{R U S}}{n_{\check{C} R}+n_{R U S}}=\frac{0,4762.609+0,44.50}{609+50}=0,4552
$$

and

$$
U=\frac{0,4762-0,44}{\sqrt{0,4552\left(1-0,45852\left(\frac{1}{609}+\frac{1}{50}\right)\right.}}=0,494
$$

and the p-value $=0.314$. The zero hypothesis (H0) cannot therefore be refuted at the significance level of 5\%. This means that the proportion of companies with an LTEP in the Czech Republic is not statistically significantly higher than that in Russia. In addition, the validity of the alternative hypothesis was not proven (the difference is not statistically significant). 
Similar comparisons were subsequently made for different combinations of countries. For the comparison between the Czech Republic and Slovakia (45 out of 85 Slovak companies had an LTEP in place) the results were as follows: U = -0.925 and the p-value $=0.823$. On this basis, the same conclusion can be drawn. For the comparison between the Czech Republic and Ukraine (29 out of 145 Ukrainian companies had an LTEP in place) the results were: $U=6.050$ and the pvalue $=7 \cdot 24 \cdot 10^{-10}$. On this basis, the opposite conclusion can be drawn. The test confirmed a statistically significant difference in the existence of an LTEP between the Czech Republic and Ukraine. For the comparison between Russia and Slovakia the results were: $U=-1.36$ and the $p$-value $=0.913$. Once again, the zero hypothesis could not be refuted. There is no statistically significant difference in the existence of an LTEP between them. For the comparison between Russia and Ukraine the results were: $U=10.53$ and the $p$-value $=0$. In this case, the zero hypothesis was refuted. The test confirmed at the significance level of 5\% that the proportion of Russian companies with an LTEP was significantly higher than the proportion of Ukrainian companies with an LTEP. For the comparison between Slovakia and Ukraine the results were: $U=17.35$ and the p-value $=0$. On this basis, the same conclusion can be drawn as in the previous case. The test confirmed that the number of companies with an LTEP in Slovakia was significantly higher than that in Ukraine.

The second step of the analysis was to look at to what extent an LTEP, where it exists, is or is not adhered to. The relevant data is presented in the following tables $(3,4)$.

Table 3. (Non-) existence of an LTEP and (non-) adherence to it (in terms of numbers of companies)

\begin{tabular}{|c|cccc|c|}
\hline & Yes & Yes/Not adhered to & No & No response & Total \\
\hline Czech Republic & 247 & 43 & 316 & 3 & 609 \\
Russia & 9 & 13 & 28 & & 50 \\
Slovakia & 40 & 5 & 40 & & 85 \\
Ukraine & 21 & 8 & 114 & 2 & 145 \\
\hline Total & 317 & 69 & 498 & 5 & 889 \\
\hline
\end{tabular}

Source: Authors

Table 4. (Non-) existence of an LTEP and (non-) adherence to it (in terms of the proportion of companies (in \%))

\begin{tabular}{|l|cccc|c|}
\hline & Yes & Yes/Not adhered to & No & No response & Total \\
\hline Czech Republic & $40.6 \%$ & $7.1 \%$ & $51.9 \%$ & $0.5 \%$ & $100.0 \%$ \\
\hline Russia & $18.0 \%$ & $26.0 \%$ & $56.0 \%$ & $0.0 \%$ & $100.0 \%$ \\
\hline Slovakia & $47.1 \%$ & $5.9 \%$ & $47.1 \%$ & $0.0 \%$ & $100.0 \%$ \\
\hline Ukraine & $14.5 \%$ & $5.5 \%$ & $78.6 \%$ & $1.4 \%$ & $100.0 \%$ \\
\hline Total & $35.7 \%$ & $7.8 \%$ & $56.0 \%$ & $0.6 \%$ & $100.0 \%$ \\
\hline
\end{tabular}

Source: Authors

An existing LTEP is most often not adhered to in Russia (26.0\%) and most often adhered to in Ukraine (5.5\%). However, in Ukraine, the non-existence of an LTEP is the highest (78.6\%) among the four countries, or garnered no response at all $(1.4 \%)$.

The third step of the analysis was to look at the existence of an AEP in companies according to country. The results are presented in the contingency tables $(5,6)$.

Table 5. Numbers of companies with and without an AEP

\begin{tabular}{|l|cc|c|}
\hline & Yes & No & Total \\
\hline Czech Republic & 293 & 316 & 609 \\
\hline Russia & 8 & 42 & 50 \\
\hline Slovakia & 46 & 39 & 85 \\
\hline Ukraine & 29 & 116 & 145 \\
\hline Total & 376 & 513 & 889 \\
\hline
\end{tabular}

Source: Authors 
Table 6. Proportion of companies with and without an AEP (in \%)

\begin{tabular}{|l|cc|c|}
\hline & Yes & No & Total \\
\hline Czech Republic & $48.1 \%$ & $51.9 \%$ & $100.0 \%$ \\
\hline Russia & $16.0 \%$ & $84.0 \%$ & $100.0 \%$ \\
\hline Slovakia & $54.1 \%$ & $45.9 \%$ & $100.0 \%$ \\
\hline Ukraine & $20.0 \%$ & $80.0 \%$ & $100.0 \%$ \\
\hline Total & $42.3 \%$ & $57.7 \%$ & $100.0 \%$ \\
\hline \multicolumn{4}{l}{ Source: Authors }
\end{tabular}

It is clear that the country with the highest number of companies with an AEP is Slovakia (54.1\%), followed in succession by the Czech Republic (48.1\%), Ukraine (20.0\%) and Russia (16.0\%). The significance of the dependence of the proportion of companies with an AEP on the country of origin was proven by a Chi-square test of independence. The results (see Table 7) were as follows: $\mathrm{X}$-squared $=57.01$; $\mathrm{df}=3$; $\mathrm{p}$-value $=2.56 .10^{-12}$. This means that the statistical significance of this dependence was confirmed at the significance level of 5\%. However, it should be noted that the results may be influenced by the low number of Russian companies in the sample set.

As before, two-selection asymptotic U-tests were conducted on the population proportions to compare the existence of an AEP in the four countries. The results are summarised in table 7 (the compared countries, selective proportions, numbers of measurements, test statistic, the p-value of the test):

Table 7. Results of U-tests - comparison of the existence of an AEP in the four countries

\begin{tabular}{|l|c|c|c|c|c|c|}
\hline & p1 & p2 & n1 & n2 & u & p-value \\
\hline CR_RUS & 0.481 & 0.16 & 609 & 50 & 4.380 & $5.940 .10^{-06}$ \\
\hline CR_SLO & 0.481 & 0.541 & 609 & 85 & -1.043 & 0.852 \\
\hline CR_UKR & 0.481 & 0.2 & 609 & 145 & 6.150 & $3.867 .10^{-10}$ \\
\hline RUS_SLO & 0.16 & 0.541 & 50 & 85 & -9.058 & 1 \\
\hline RUS_UKR & 0.16 & 0.2 & 50 & 145 & -1.755 & 0.960 \\
\hline SLO_UKR & 0.541 & 0.2 & 85 & 145 & 17.978 & 0 \\
\hline
\end{tabular}

Source: Authors

On the basis of the results presented in Table 7, it can be concluded that the zero hypothesis on the existence of an AEP can only be refuted for the following comparisons: Czech Republic - Russia; Czech Republic - Ukraine; and Slovakia - Ukraine. This means that the proportion of companies within a country that have an AEP is significantly higher in the Czech Republic than in Russia and Ukraine and is significantly higher in Slovakia than in Ukraine. The differences are not significant between the remaining pairs of countries.

The dependence of the existence of an LTEP on country and company size was subsequently analysed.

The results are presented hierarchically in the contingency tables $(8,9)$ that follow.

Table 8. Number of companies with an LTEP according to country and company size

\begin{tabular}{|l|c|c|c|}
\hline & Yes & No & Total \\
\hline Czech Republic & $\mathbf{2 9 0}$ & $\mathbf{3 1 9}$ & $\mathbf{6 0 9}$ \\
\hline micro-company & 35 & 107 & 142 \\
\hline small company & 77 & 103 & 180 \\
\hline medium-sized company & 89 & 75 & 164 \\
\hline large company & 89 & 34 & 123 \\
\hline Russia & $\mathbf{2 2}$ & $\mathbf{2 8}$ & $\mathbf{5 0}$ \\
\hline micro-company & 3 & 10 & 13 \\
\hline small company & 17 & 17 & 34 \\
\hline medium-sized company & 2 & 1 & 3 \\
\hline Slovakia & $\mathbf{4 5}$ & $\mathbf{4 0}$ & $\mathbf{8 5}$ \\
\hline
\end{tabular}




\begin{tabular}{|l|c|c|c|}
\hline micro-company & 5 & 8 & 13 \\
\hline small company & 11 & 19 & 30 \\
\hline medium-sized company & 15 & 11 & 26 \\
\hline large company & 14 & 2 & 16 \\
\hline Ukraine & $\mathbf{2 9}$ & $\mathbf{1 1 6}$ & $\mathbf{1 4 5}$ \\
\hline micro-company & 3 & 25 & 28 \\
\hline small company & 5 & 26 & 31 \\
\hline medium-sized company & 11 & 44 & 55 \\
\hline large company & 10 & 21 & 31 \\
\hline Total & $\mathbf{3 8 6}$ & $\mathbf{5 0 3}$ & $\mathbf{8 8 9}$ \\
\hline
\end{tabular}

Source: Authors

Table 9. Proportion of companies with an LTEP according to country and company size (in \%)

\begin{tabular}{|l|c|c|c|}
\hline & Yes & No & Total \\
\hline Czech Republic & $\mathbf{4 7 . 6 \%}$ & $\mathbf{5 2 . 4 \%}$ & $\mathbf{1 0 0 . 0 \%}$ \\
\hline micro-company & $24.6 \%$ & $75.4 \%$ & $100.0 \%$ \\
\hline small company & $42.8 \%$ & $57.2 \%$ & $100.0 \%$ \\
\hline medium-sized company & $54.3 \%$ & $45.7 \%$ & $100.0 \%$ \\
\hline large company & $72.4 \%$ & $27.6 \%$ & $100.0 \%$ \\
\hline Russia & $\mathbf{4 4 . 0 \%}$ & $\mathbf{5 6 . 0 \%}$ & $\mathbf{1 0 0 . 0 \%}$ \\
\hline micro-company & $23.1 \%$ & $76.9 \%$ & $100.0 \%$ \\
\hline small company & $50.0 \%$ & $50.0 \%$ & $100.0 \%$ \\
\hline medium-sized company & $66.7 \%$ & $33.3 \%$ & $100.0 \%$ \\
\hline Slovakia & $\mathbf{5 2 . 9 \%}$ & $\mathbf{4 7 . 1 \%}$ & $\mathbf{1 0 0 . 0 \%}$ \\
\hline micro-company & $38.5 \%$ & $61.5 \%$ & $100.0 \%$ \\
\hline small company & $36.7 \%$ & $63.3 \%$ & $100.0 \%$ \\
\hline medium-sized company & $57.7 \%$ & $42.3 \%$ & $100.0 \%$ \\
\hline large company & $87.5 \%$ & $12.5 \%$ & $100.0 \%$ \\
\hline Ukraine & $\mathbf{2 0 . 0 \%}$ & $\mathbf{8 0 . 0 \%}$ & $\mathbf{1 0 0 . 0 \%}$ \\
\hline micro-company & $10.7 \%$ & $89.3 \%$ & $100.0 \%$ \\
\hline small company & $16.1 \%$ & $83.9 \%$ & $100.0 \%$ \\
\hline medium-sized company & $20.0 \%$ & $80.0 \%$ & $100.0 \%$ \\
\hline large company & $32.3 \%$ & $67.7 \%$ & $100.0 \%$ \\
\hline Total & $\mathbf{4 3 . 4 \%}$ & $\mathbf{5 6 . 6 \%}$ & $\mathbf{1 0 0 . 0 \%}$ \\
\hline Source: Authors & & & \\
\hline
\end{tabular}

The results reveal that the proportion of companies with an LTEP grows significantly with company size in the Czech Republic and in Russia, whilst this growth is less significant in Slovakia and Ukraine.

The dependence of the proportion of companies with an LTEP on country and the scope of company activity was subsequently analysed. The results are presented in the contingency tables $(10,11)$ that follow.

Table 10. Numbers of companies with a LTEP according to country scope of company activity

\begin{tabular}{|l|c|c|c|}
\hline & Yes & No & Total \\
\hline Czech Republic & $\mathbf{2 9 0}$ & $\mathbf{3 1 9}$ & $\mathbf{6 0 9}$ \\
\hline multinational & 108 & 79 & 187 \\
\hline national & 82 & 96 & 178 \\
\hline regional & 99 & 143 & 242 \\
\hline (vacant) & 1 & 1 & 2 \\
\hline
\end{tabular}




\begin{tabular}{|l|c|c|c|}
\hline Russia & $\mathbf{2 2}$ & $\mathbf{2 8}$ & $\mathbf{5 0}$ \\
\hline multinational & 5 & 2 & 7 \\
\hline national & 5 & 6 & 11 \\
\hline regional & 12 & 20 & 32 \\
\hline Slovakia & $\mathbf{4 5}$ & $\mathbf{4 0}$ & $\mathbf{8 5}$ \\
\hline multinational & 14 & 16 & 30 \\
\hline national & 16 & 10 & 26 \\
\hline regional & 15 & 14 & 29 \\
\hline Ukraine & $\mathbf{2 9}$ & $\mathbf{1 1 6}$ & $\mathbf{1 4 5}$ \\
\hline multinational & 10 & 20 & 30 \\
\hline regional & 19 & 96 & 115 \\
\hline Total & $\mathbf{3 8 6}$ & $\mathbf{5 0 3}$ & $\mathbf{8 8 9}$ \\
\hline Sorce Aurs
\end{tabular}

Source: Authors

Table 11. Proportion of companies with an LTEP according to country and scope of company activity

\begin{tabular}{|l|c|c|c|}
\hline & Yes & No & Total \\
\hline Czech Republic & $\mathbf{4 7 . 6 \%}$ & $\mathbf{5 2 . 4 \%}$ & $\mathbf{1 0 0 . 0 \%}$ \\
\hline multinational & $57.8 \%$ & $42.2 \%$ & $100.0 \%$ \\
\hline national & $46.1 \%$ & $53.9 \%$ & $100.0 \%$ \\
\hline regional & $40.9 \%$ & $59.1 \%$ & $100.0 \%$ \\
\hline (vacant) & $50.0 \%$ & $50.0 \%$ & $100.0 \%$ \\
\hline Russia & $\mathbf{4 4 . 0 \%}$ & $\mathbf{5 6 . 0 \%}$ & $\mathbf{1 0 0 . 0 \%}$ \\
\hline multinational & $71.4 \%$ & $28.6 \%$ & $100.0 \%$ \\
\hline national & $45.5 \%$ & $54.5 \%$ & $100.0 \%$ \\
\hline regional & $37.5 \%$ & $62.5 \%$ & $100.0 \%$ \\
\hline Slovakia & $\mathbf{5 2 . 9 \%}$ & $\mathbf{4 7 . 1 \%}$ & $\mathbf{1 0 0 . 0 \%}$ \\
\hline multinational & $46.7 \%$ & $53.3 \%$ & $100.0 \%$ \\
\hline national & $61.5 \%$ & $38.5 \%$ & $100.0 \%$ \\
\hline regional & $51.7 \%$ & $48.3 \%$ & $100.0 \%$ \\
\hline Ukraine & $\mathbf{2 0 . 0 \%}$ & $\mathbf{8 0 . 0 \%}$ & $\mathbf{1 0 0 . 0 \%}$ \\
\hline multinational & $33.3 \%$ & $66.7 \%$ & $100.0 \%$ \\
\hline regional & $16.5 \%$ & $83.5 \%$ & $100.0 \%$ \\
\hline Total & $\mathbf{4 3 . 4 \%}$ & $\mathbf{5 6 . 6 \%}$ & $\mathbf{1 0 0 . 0 \%}$ \\
\hline Source: Authors & & &
\end{tabular}

In the majority of countries (with the exception of Slovakia), the highest proportion of companies with an LTEP were multinationals, whereby the highest proportion was in Russia (71.4\%), and the lowest proportion of companies with an LTEP were regional companies, whereby the lowest proportion was in Ukraine (16.5\%).

The dependence of the median proportion of companies with an LTEP on the number of employees was examined by means of a regression analysis. An artificial variable $y$, which achieves the value 1 for a company with an LTEP and the value 0 for a company without an LTEP, was used as the alternative LTEP variable. The number of employees $(x)$ of a company was used as the explanation variable. Because a linear regression model does not have good properties, a logit model was used instead. In the logit model, the dependence was modelled on the basis of a logistic regression function. The logit model took the following form:

$y_{\mathrm{i}}=\frac{1}{1+\mathrm{e}^{-\left(\beta_{0}+\beta_{1} x_{\mathrm{i}}+\varepsilon_{\mathrm{i}}\right)}}$,

where $\varepsilon \mathrm{i}, \mathrm{i}=1, \ldots \mathrm{n}$, are random components. The estimated form of the model was $\hat{y}_{\mathrm{i}}=p_{\mathrm{i}}=\frac{1}{1+\mathrm{e}^{-\left(b_{0}+b_{1} x_{\mathrm{i}}\right)}}$, 
where $p i$ are the probability estimations, $\mathrm{P}(\mathrm{Y}=1 \mid \mathrm{xi}), \mathrm{i}=1, \ldots, \mathrm{n}$ a b0, b1 are estimations of parameters $\beta 0, \beta 1$. The expression on the right side of the equation represents the distribution function of a logistic random value. The model was subsequently transformed by means of logarithmic transformation into the following linear form:

$$
\hat{L}_{i}=\ln \frac{p_{\mathrm{i}}}{1-p_{\mathrm{i}}}=b_{0}+b_{1} x_{\mathrm{i}}
$$

The left sides of this equation $\hat{L}_{\mathrm{i}}$ are so-called estimated logits. It is a linear model with variables $L_{i}$ and $x_{i}$. The logits are the logarithms of the chances of condition $Y=1$ (an LTEP exists in the company) and are linear functions with regression parameters. The interpretation of the coefficient $b_{l}$ is as follows: if the variable $x$ changes by one unit, then the logit changes by $b_{1}$ units. This means that the chance (i.e. the proportion $\mathrm{p} /(1-\mathrm{p})$ ) of condition $\mathrm{Y}=1$ will be $\exp \left(b_{1}\right)$ times greater. The absolute member $b_{0}$ is equal to the chance of condition $\mathrm{Y}=1$, if the explanation variable is zero. As there is heteroskedasticity in the model, the regression coefficients in the R programme were estimated by means of the maximum likelihood (MLE) method. The maximum likelihood estimation was obtained by maximising the combined distribution (or in fact its natural logarithm) of a selection of the explanatory variables.

If the artificial variables $i$ are also for the categorical variable state, the logit model can be used to express the dependence of the proportion of companies with an LTEP on the number of employees and on country. The result is dependence expressed in the form of the following logistic functions for each country:

Czech Republic

Russia

Slovakia

Ukraine

$$
\begin{aligned}
& p=1 /(1+\exp -(-0.479+0.00212 x) \\
& p=1 /(1+\exp -(-1.325+0.0635 x) \\
& p=1 /(1+\exp -(-0.295+0.00286 x) \\
& p=1 /(1+\exp -(-1.717+0.00101 x)
\end{aligned}
$$

as presented in the graph below.

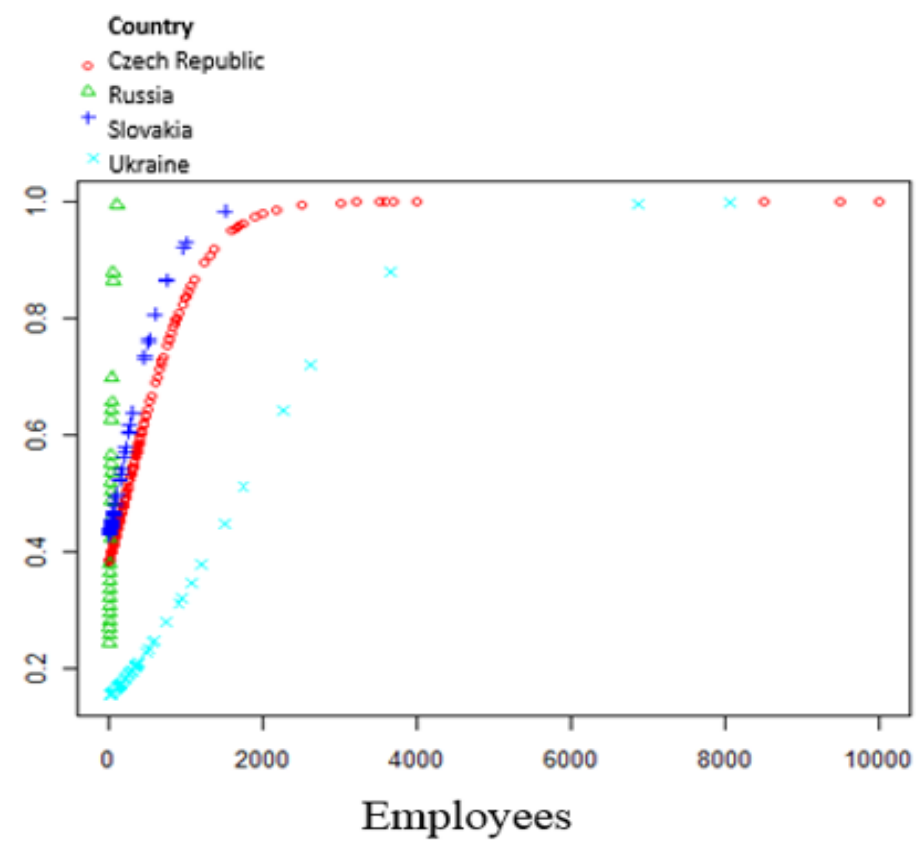

Graph 1. Dependence of the proportion of companies $p$ with an LTEP on the number of employees $x$ and on country Source: Authors

As is evident in Figure 1, the proportion of companies with an LTEP grows significantly. With the exception of Slovakia, the estimations of the regression coefficients are statistically significant.

In a similar way, the logit model was subsequently used to estimate the dependence of the proportion of companies with an AEP on the number of employees and on country. The result is dependence expressed in the form of the following logistic functions for each country:

\section{Czech Republic}

Russia

Slovakia

Ukraine

$$
\begin{aligned}
& \mathrm{p}=1 /(1+\exp -(-0,682+0,00441 \mathrm{x}) \\
& \mathrm{p}=1 /(1+\exp -(-2,486+0,0404 \mathrm{x}) \\
& \mathrm{p}=1 /(1+\exp -(-0,441+0,00484 \mathrm{x}) \\
& \mathrm{p}=1 /(1+\exp -(-2,100+0,00281 \mathrm{x})
\end{aligned}
$$

as presented in the graph below. 


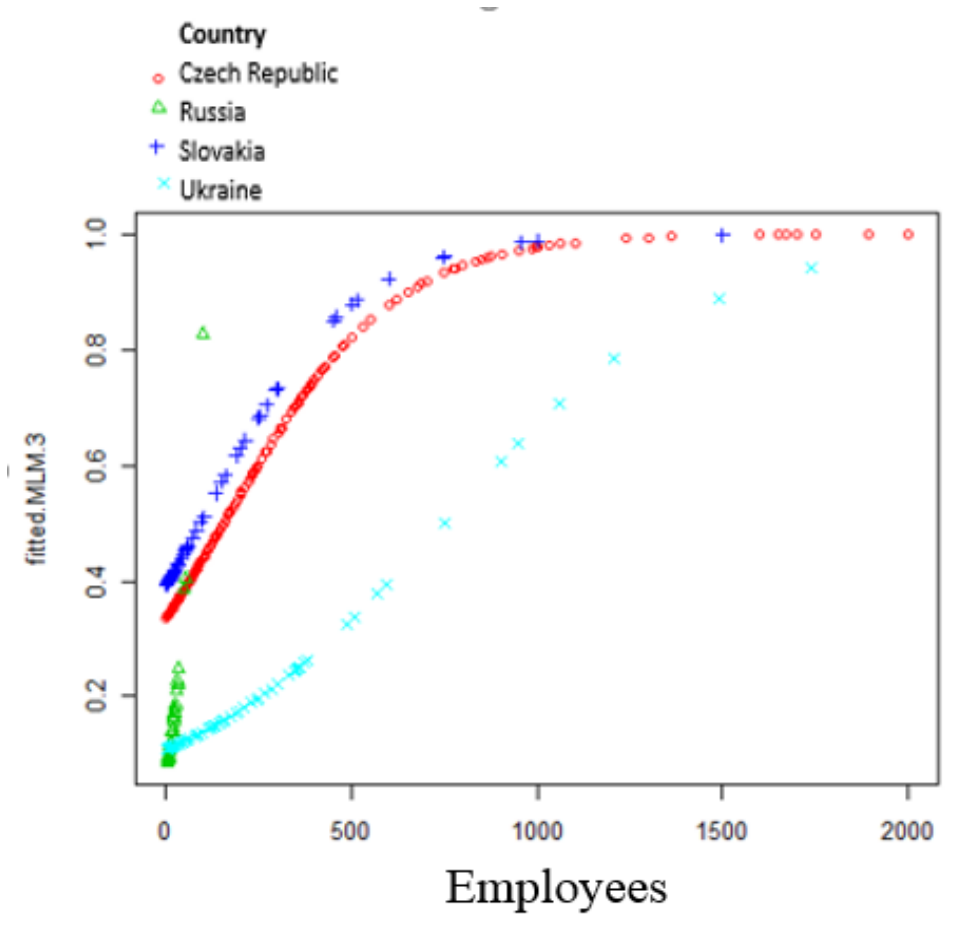

Graph 2. Dependence of the proportion of companies $p$ with an AEP on the number of employees $x$ and on country Source: Authors

The conclusions with regards to the dependence are identical to the conclusions from the previous model.

The basic precondition for successful corporate education is a strategic approach and planning. The research survey conducted in four post-communist countries showed that micro-companies and small companies in particular do not do so. This finding is consistent with the results of an international survey in which less than a third of companies reported having written education plans or similar education programmes in place [12].

The research also showed that some companies, even though they declare they have an LTEP/AEP in place, are not adhering to their plans.

\section{Conclusion}

The proportion of companies in which an LTEP exists in the Czech Republic is $47.6 \%$, in Russia 44\%, in Slovakia $52.9 \%$ and in Ukraine $20.0 \%$. Tests on the proportions revealed that only the differences between Ukraine and the other countries were statistically significant and between the other countries insignificant. By means of a Chi-square test of independence it was shown that the existence of an LTEP and an AEP in a company statistically significantly depends on the country. The proportion of companies which have an LTEP in Slovakia was $54.1 \%$, in the Czech Republic $48.1 \%$, in Ukraine $20.0 \%$, and in Russia only $16.0 \%$. Tests revealed that the percentage difference with regards to the presence of an LTEP was only statistically significant between the Czech Republic and Russia, between the Czech Republic and Ukraine, and between Slovakia and Ukraine.

The adherence to an LTEP by companies in the individual countries was also analysed. In contrast to the other countries, the proportion of companies with an LTEP in the Czech Republic statistically significantly grows with the size of the company (from $24.6 \%$ among micro-companies to $72.4 \%$ among large companies). The case is similar with regards to the scope of a company's activities, i.e. the proportion of companies with an LTEP in the Czech Republic also statistically significantly grows with the scope of a company's activities, unlike in the other countries.

The quantitatively expressed dependence of the median proportion of companies with an LTEP and/or AEP on the number of employees was obtained by means of logistic regression. The dependence for each country was expressed by a formula (used for prediction purposes) and illustrated graphically. As the graphs indicate, a significant growth in the existence of an LTEP as well as an AEP was proven for the companies in all the countries, with exception to Slovakia.

The key precondition for effective corporate education is a strategic approach and planning. The research survey showed that micro-companies and small companies in particular do not do so.

The research also showed that some companies, even though they declare they have an LTEP/AEP in place, are not adhering to their plans. 
Acknowledgement: This paper is a partial output of the project no. SV202102R: Analysis of corporate education on a selected sample of companies of various size categories in the Czech Republic and of the project IVSUPS 003 "Current Trends in Human Resource Management”.

\section{References}

1. Y.-H. Wang, S.-B. Zhou, Research on Managers' Training Needs of Small Medium-sized Enterprises in Mainland A Case Study of Chongqing. Proceedings of the International Conference on Human Resource, Organizational Behavior and Leadership, London, United Kingdom of Great Britain and Northern Ireland, 157-160 (2009)

2. S. Akrofi, Evaluating the effects of executive learning and development on organisational performance: implications for developing senior manager and executive capabilities. International Journal of Training and Development, 20(3), 177-199 (2016)

3. M. Armstrong, Armstrong's handbook of human resource management practice. Philadelphia: Kogan Page Ltd, (2014)

4. A. R. Masalimova, M. Usak, A. R. Shaidullina, Advantages and Disadvantages of National and International Corporate Training Techniques in Adult Education. Current Science, 111(9), 1480-1485 (2016)

5. R. Blahuš, Experiential Education as a Part of Human Development in Czech Republic Business Companies. Proceedings of the 7th European Conference on Management Leadership and Governance, Antibes, France, 467476 (2011)

6. J. Kirkpatrick, W. K. Kirkpatrick, The Kirkpatrick Four Levels: A Fresh Look After 50 Years 1959 - 2009. [s. 1.]: Kirkpatrick Partners, LLC (2009)

7. Chernykh, S.I., Parshikov, V.I. Corporate education abroad: Social and philosophical analysis. International Review of Management and Marketing [online]. Econjournals, volume 6, Issue 6, 2016, pp. 272-277 (2016)

8. JI, X. Study on Corporate Training Quality Monitoring. In: Proceedings of the 2015 Conference on Informatization in Education, Management and Business. Paris: ATLANTIS PRESS, 2015, pp. 356-359 (2015).

9. A. Bencsik, A. Sólyom, Education and Training Practice Strategies in Small and Medium Sized Enterprises. Proceedings of the 6th International Conference on Management and Artificial Intelligence, Bali, Indonesie, 65-69 (2011)

10. A. Rauch, A., Hatak, I.. A meta-analysis of different HR-enhancing practices and performance of small and medium sized firms. Journal of Business Venturing, 31(5), 485-504 (2016)

11. U. Moideenkutty, U., Murthy, Y. S. R., Al-Lamky, A. Localization HRM practices and financial performance: Evidence from the Sultanate of Oman. Review of International Business and Strategy, 26(3), 431-442 (2016)

12. Czech Statistical Office, Further Vocational Education of Employed Persons in 2010 (CVTS). Prague: Czech Statistical Office (2013)

13. International Labour Organization, A Skilled Workforce for Strong, Sustainable and Balanced Growth: A G20 Training Strategy. Geneva: International Labour Organization, (2011)

14. W. Collier, F. Green, Y.-B. Kim, J. Peirson, Education, Training and Economic Performance: Evidence from Establishment Survival Data. Journal of Labor Research, 32(4), 336-361 (2011)

15. J. Kitching, R. Blackburn, The Nature of Training and Motivation to Training in Small Firms. Kingston upon Thames: Small Business Research Centre at Kingston University, (2002)

16. M. Korenková, Vplyv regionálnych rozdielností na možnost’ vzdelávania sa zamestnancov v podniku. Proceedings of the 17th International Colloquium on Regional sciences, Brno, Czech Republic, 264-269 (2014)

17. J. Tej, G. Sláviková, M. Hrvolová, Vybrané kapitoly z manažmentu l’udských zdrojov. Dubnice nad váhom: Dubnický technologický inštitút v Dubnici nad Váhom, (2010)

18. D. Cagáňová, M. Čambál, K. Stachová, Z. Stacho, Education of Employees in Organisations in Slovakia. Electronic Journal of Knowledge Management, 12(4), 210-220 (2014)

19. D. N. Gujarati, C. P. Dawn, Basic Econometrics. Fifth ed. New York: Mc Grow-Hill, (2008)“

20. Z. Caha and J. Urban, Human Resource Management in SMEs in the Czech Republic - specifics and key requirements. SHS Web of Conferences (2020) 